\title{
How to Use Qilu-Folk Dyeing Fabric on the Silk Clothing Design
}

\author{
Jielin Liu \\ Jiangxi Environmental Engineering Vocational College, Ganzhou, 341000, China
}

\begin{abstract}
Keywords: Silk clothing design Qilu culture Folk dyeing fabric Traditional culture
\end{abstract}
\begin{abstract}
Qilu-culture is a typical representative of Shandong folk culture, can shows the the unique way of the production and life of the people in Shandong region, can profoundly reflect the local people's living habits. With the help of unique shape, color, texture and process of Qilu-dyeing-fabric, this paper proposes some fashion design method with the local folk. The specific design practice show that melting Qilu-Folk dyeing fabric into Silk clothing design has a very distinctive local color, and melting Qilu-Folk dyeing fabric elements into modern fashion design concept can enhance people's love for traditional culture, release the hearts of the people, make the clothing design more folk flavor.
\end{abstract}

\section{Introduction}

The modern silk clothing design has long history culture and regional culture, and has become a typical representative of recording Chinese rich historical and cultural connotation, inheriting Chinese traditional clothing charm. Qilu Folk dyeing fabric has formed a regional folk art form in its development process, is indispensable daily arts and crafts, also is a non material cultural heritage, has an important role in inheriting traditional culture of our country, showing the Qilu-Folk dyeing fabric characteristics, and the modern fashion design charm, is full of Emotional destination of ecological civilization.

\section{The significance and value of modern silk Clothing design}

Silk clothing is a concentrated reflection of our ancient traditional culture essence, it is still able to retain its style after a lot years of baptism, so silk has the natural outpouring of soft, elegant style., it makes us have a yearning for more elegant affection of clothing. At present, the development of silk clothing has begun to be integrated with the modern fashion design, and forming a rich and unique design style and design perspective, while focus on the display of different styles of clothing, at same time it can also be bold and innovative, becoming diversified in the design form. This design innovation is built in the native culture. With folk costume culture elements and modelling of stand-up collar, double-breasted, flower, combining with embroidery, paper cutting and other forms of folk art, the design make the clothing design of core concepts and techniques more diverse. Modern silk clothing design realized across the China Millennium national costume culture artistic conception, created graceful, subtle, gentle, nostalgic, romantic and creative, inherit and development the China's ancient traditional culture charm.

Qilu-Folk dyeing fabric also has a prolific artistic elements, these artistic elements can reflect the real life of the Qilu region, reflects the strong local culture and the simple artistic characteristics, is the most representative of the essence of the Qilu culture [1], and has played an important role in promoting the development of local clothing design. The integration of Qilu culture and modern fashion design has become the basis of the design of clothing, makes the modern fashion design field more extensive and concrete, so that people can understand the traditional culture of China. The Qilu-Folk dyeing fabric cultural elements rooted in China's silk garment design concept, is become a try and extend of the silk clothing products $\mathrm{R} \& \mathrm{D}$ and innovation, has become an effective means of modern garment design and development, and has a very broad and specific characteristics. 


\section{The Composition and affective characteristics of The Qilu-Folk dyeing fabric}

Through the above discussion, we can understand that, Qilu-Folk dyeing fabric, which has folk flavor design elements, has a positive reference to silk clothing design. And The Qilu-Folk dyeing fabric must have the unique structure and emotional characteristics, it is because of these characteristics, which makes The Qilu-Folk dyeing fabric has become a typical clothing design elements [2].

The typical structure of the Qilu-Folk dyeing fabric is blue printed cloth and multicolor printed cloth. Especially the color printing cloth is the most representative and the artistic charm, it can fully show the characteristics of the folk art of Qilu area. The characteristics of the Qilu-Folk dyeing fabric is:

a). The structure of the layout is rigorous, layout is symmetrical, whether the main texture or the pattern of the secondary texture is very distinct, and the skeleton feature is: Separate stripe style, two party, continuous, square, etc., a variety of combinations of texture patterns are formed on the basis of this framework.take point, line, surface as a continuous basis, formed symmetric, spacing and communicated with each other. Through many simple geometry to achieve a realistic texture design style, make the picture more realistic and three-dimensional.

b). The texture style is richer, the most common style of the texture is animal and plant material such as Lotus, chrysanthemum, peony, butterfly, crane and other. The following figure 1 is a common patterns, it is the lotus and carp, can give a strong sense of the simple picture.

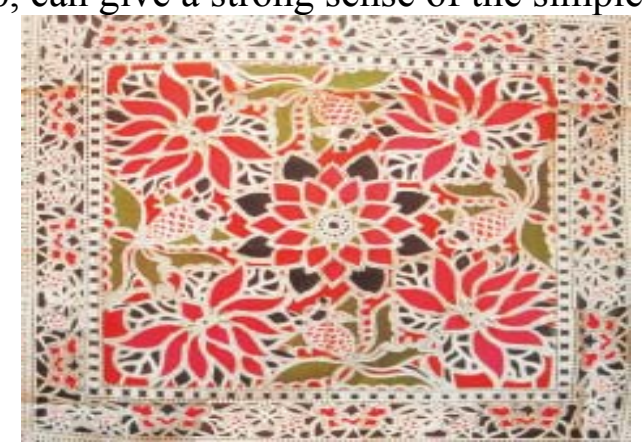

Fig. 1 The lotus and carp picture

c). Take Bright multicolor as main, For example, taking red, green, blue, yellow and other folk color system as the predominant color is a very strong sense of decoration and painting, it is very common in people's daily life in the Qilu region

d). The technology is very exquisite, the production process has strict requirements, take fabric, material, etc. as the tested target in the production process, and the expression form is symmetry [3].

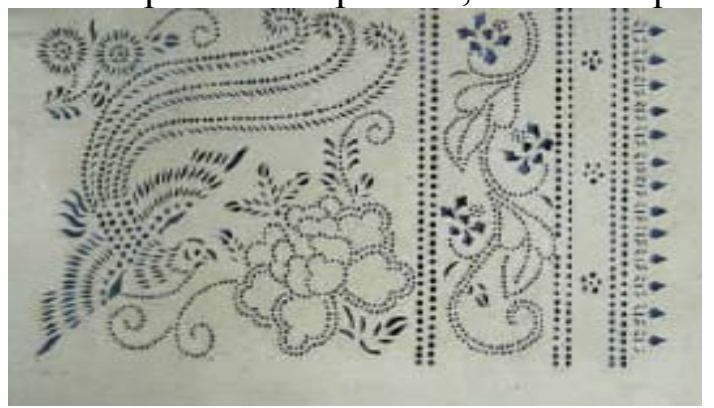

Fig. 2 Qilu folk blue calico style

e). The meaning of folklore is interesting, In Qilu area, there are many dyeing fabric can reflect the animal or plant combination, this combination can reflect the specific meaning, metaphor, homophonic and other art forms. Selecting the typical local folk legend, auspicious patterns as a typical symbol, reflects that the people reposed a better life. 


\section{The application of modern silk clothing design}

The Shape of Folk dyeing fabric in Qilu region can reflect the pattern, all kinds of color and handicrafts, etc., these will be fully integrated into a distinctive design style. In modern silk clothing design, the application of Folk dyeing fabric in Qilu region is analyzed at follow.

\section{The use of modeling elements}

Integrated modeling

The modern silk clothing design can reflect the Times characteristic and the rich local flavor of The Qilu-Folk dyeing fabric. The personalized tailoring can Enhance the sense of line and smooth, enhance the artistic conception, and show the unique flavor of the model, Figure 3 shows Sense of hierarchy and elegant. Convey a sense of tradition and modernity coexist with strong collocation effect.

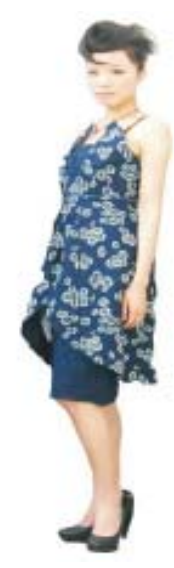

Fig. 3 Silk clothing mix design style

There are some clothing design form can divide the structure of The Qilu-Folk dyeing fabric, and then bring a strong sense of contrast and three-dimensional effect, Can retain the layout features of Qilu folk blue calico, show the characteristics of three-dimensional modeling of Modern silk clothing design, reflects the overall style of clothing and not to stick at trifles. The use of unique elements of The Qilu-Folk dyeing fabric provides a new perspective on the integration of folk culture and modern culture, promotes the innovation and breakthrough of the silk clothing overall modeling.

Local modeling of clothing

The Local modeling of clothing is mixing the Design details of the Qilu-Folk dyeing fabric and the silk clothing design. Through splicing, piping, decoration etc. reflect different design angle and design Charm. For example, the design of the collar, pockets, and other parts of the placket.

A). Collar design. Combined with regional characteristics, to emphasize the texture effect of the clothing surface, and reflect the fun of modelling.

b).Pocket design. In order to meet the maximum practical needs, to achieve the unity of the size, location and shape, to highlight the contrast visual effect.

c). Sleeve design. To optimize the molding and ornamental style, and then make sure that the line is smoother, full, and reflecting a sense of rhythm.

d).Shoulder design. The structure need to be mutative, front shoulder, overarm and other parts need to do a good cutting and combination, to dispel the boring and monotonous feeling, and the soft characteristics of shoulder can be revealed.

e).Placket design. According to the composition of the point, line and face, to make the shape of the visual sense and the overall design style Consistent, make the clothing in sense of simplicity and generosity.

f).Waist design. In the design process of waist, to reflect the characteristics of stability, and coordinate with the chest, make the waist design is more comfortable and soft feeling.

g).Sideways design. Choose the appropriate proportion of the geometric designs, so that it has a very strong "visual" artistic characteristics, so that the artistic image can be reflected. 
h). The design of the edge. All kinds of edge in the clothing design is also the key. For example, cuffs and hemline, pants and other common parts. In the design process, the Suitable element make the clothing with more dynamic, reflect the rich local customs. The layout and design process can reflect the different styles of visual effects.

\section{The use of pattern elements}

The patterns Types of The Qilu-Folk dyeing fabric are very many, is Effective used in silk clothing design, fully reflect the distinctive silk fashion design style, extract The typical pattern elements, with the help of the local characteristics of animal, plant, landscape and suitable framework, and then form a clear, harmonious of the decorative structure. Besides, with the sign, euphony, symbolic of The Qilu-Folk dyeing fabric, show allegorical propitious harmonious, harvest, happiness, etc., express the rich emotional in the heart of people, created the visual beauty and cultural beauty of the silk clothing design.

\section{The use of color elements}

Integrating The Qilu-Folk dyeing fabric into fashion design can reflect the Chinese folk color aesthetic characteristics, show the high purity of the contrast color picture, and express the local people's simple feelings. Through the combination of a large number of colorless and colored lines to produce personalized decorative effect, and contact with modern silk garment color design, reflect the diversity of modern silk garment color design, and adapt to the psychological of people. Figure 4 is ice tray chrysanthemum pattern of The Qilu-Folk dyeing fabric, it Main applies in the design of male silk jacket, To form a dynamic effect by the collar, sleeves, buttons and other color modeling and collocation, The idea of creative design can be extended, and the rich implication of emotion is explained. This style can show the local people's hard-working, honest and simple nature.

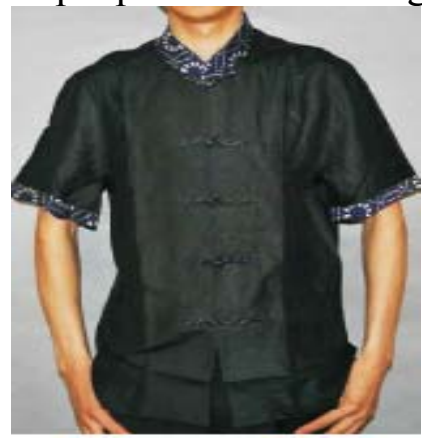

Fig. 4 Male silk jacket design

\section{Application of fabric processing method}

Qilu area is rich in cotton, so the local dyeing fabric mostly is made of cotton fabric, applies natural dyes, and use hand making traditional fabrics. The modern silk garment fabric is take Slip as mark, the combination of the two will have a strong contrast, which restricts the development of modern silk garment design.so in the silk garment design, to strengthen the process of innovation, the two can be fully integrated. First, To make innovations in the configuration and operation of dyes, application of dyed, to apply step by step, part by part and splash dyeing techniques, thus forming shallow, colorful and beautiful color, pattern and texture effect, so as to realize the unity of art and practical, reflect the appearance of coordination of silk garment. Secondly, using clothing technology means such as stitching, stitching, segmentation, nail repair, digging, scattered etc., in fabrics, technology structure, reflect the art atmosphere by color and shape. For example, in the evening dress design can use the splicing process design, fabrics contrast can be compensated by the interaction of The Qilu-Folk dyeing fabric and silk fabrics. 


\section{Concluding remarks}

After the combination of The modernization of silk clothing design and The Qilu-Folk dyeing fabric design elements with regional characteristics, Many characteristics of folk art of The Qilu-Folk dyeing fabric will combine to modern silk garment design and innovation, For example, beautiful shape, personalized color, meaning deep patterns, exquisite handicrafts, etc., This fusion style and artistic elements not only makes the Qilu folk printing and dyeing cloth development with inheritance, can also make the impression of modern silk garment design language to be rich, for the modernization of silk clothing to add a different kind of charm.

\section{References}

[1] Chen xianjin. Elegant Fu blue and white Qiaoran cotton send nostalgia - Nantong blue calico history and characteristics. Hundreds of Arts, 2011 (2): 123-124.

[2].Tu Wei Folk Art Appreciation Series eight Jiangsu folk art appreciation, Nantong blue calico. The Chinese art education, 2012 (6): 92-96.

[3] Chai Songhua. Lucky numbers "2" in the Western blue cloth pattern performance -- with folk commonly known as the "four dishes and one soup" pattern of blue calico for cases. Popular literature, 2012 (15): 100 - 101.

[4] Chen Quyan. The protection of national non material cultural heritage to carry forward the Chinese ancient folk traditional culture -- Taking Nantong blue calico cases. The Chinese culture, 2012 (4): 4 